\title{
UNIVERSITYOF
}

FORWARD

THINKING

WESTMINSTER用

WestminsterResearch

http://www.westminster.ac.uk/westminsterresearch

Carbohydrate intake and ketosis in self-sufficient multi-stage

ultramarathon runners

Edwards, K., Elliott, B. and Silva, C.

This is an accepted manuscript of an article published by Taylor \& Francis in Journal of Sports Sciences, DOI: 10.1080/02640414.2019.1702269.

The final definitive version is available online:

https://dx.doi.org/10.1080/02640414.2019.1702269

(C) 2019 Taylor \& Francis

The WestminsterResearch online digital archive at the University of Westminster aims to make the research output of the University available to a wider audience. Copyright and Moral Rights remain with the authors and/or copyright owners.

Whilst further distribution of specific materials from within this archive is forbidden, you may freely distribute the URL of WestminsterResearch: ((http://westminsterresearch.wmin.ac.uk/).

In case of abuse or copyright appearing without permission e-mail repository@westminster.ac.uk 
1 Carbohydrate intake and ketosis in self-sufficient multi-stage ultramarathon 2 runners

3

4 Kate H. Edwards ${ }^{\mathrm{a}}$, ${ }^{*}$, Bradley T. Elliott ${ }^{\mathrm{a}}$, Cecilia M. Kitic ${ }^{\mathrm{b}}$

5

6

a. Translational Physiology Research Group, School of Life Sciences, University of 7 Westminster, London, UK

8

b. Sports Performance Optimisation Research Team, School of Health Sciences, University

9 of Tasmania, Australia

10

11 *Corresponding Author:

12 Kate H Edwards: University of Tasmania, Sport Performance Optimisation Research Team,

13 School of Health Sciences, Locked Bag 1322, Launceston, Tasmania, Australia

14 Email: kate.edwards0@utas.edu.au Telephone: +61 363243999

15

16

17 Abstract Word Count: 198

18 Main Body Word Count: 5017

19

20

21

22

23

24

25

26 


\section{Carbohydrate intake and ketosis in self-sufficient multi-stage ultramarathon}

runners

Abstract

Ultra-endurance athletes accumulate an energy deficit throughout their events and those competing in self-sufficient multi-stage races are particularly vulnerable due to load carriage considerations. Whilst urinary ketones have previously been noted in ultra-endurance exercise and attributed to insufficient carbohydrate $(\mathrm{CHO})$ availability, not all studies have reported concomitant $\mathrm{CHO}$ intake. Our aim was to determine changes in blood glucose and $\beta$ hydroxybutyrate concentrations over five days $(240 \mathrm{~km})$ of a self-sufficient multi-stage ultramarathon in combination with quantification of energy and macronutrient intakes, estimated energy expenditure and evaluation of energy balance. Thirteen runners ( 8 male, 5 female, mean age $40 \pm 8$ years) participated in the study. Glucose and $\beta$-hydroxybutyrate were measured every day immediately post-running, and food diaries completed daily. CHO intakes of $301 \pm 106$ $\mathrm{g} \cdot \mathrm{day}^{-1}\left(4.3 \pm 1.8 \mathrm{~g} \cdot \mathrm{kg}^{-1} \cdot \mathrm{day}^{-1}\right)$ were not sufficient to avoid ketosis (5-day mean $\beta$ hydroxybutyrate: $\left.1.1 \pm 0.6 \mathrm{mmol} . \mathrm{L}^{-1}\right)$. Furthermore, ketosis was not attenuated even when CHO 44 intake was high $\left(9 \mathrm{~g} \cdot \mathrm{kg}^{-1} \cdot \mathrm{day}^{-1}\right)$. This suggests that competing in a state of ketosis may be inevitable during multi-stage events where load reduction is prioritised over energy provisions. Attenuating negative impacts associated with such a metabolic shift in athletes unaccustomed to $\mathrm{CHO}$ and energy restriction requires further exploration.

Key words: ketones, running, ultra-endurance, carbohydrate, performance, nutrition, energy deficit 
Self-sufficient multi-stage ultramarathons are conducted over multiple days and athletes must carry all necessary clothing, equipment, and food required for the race in a backpack. Extreme environments, rough sleeping conditions and increased load carriage from backpacks result in long days of high physical, mental and emotional effort. It is recognised that many participants in ultra-endurance races compete in a state of negative energy balance and insufficient carbohydrate intake (Costa et al. 2013; Wardenaar et al. 2015). The reasons have been well explored elsewhere (Costa et al. 2016; Costa et al. 2017; Stuempfle and Hoffman 2015; Stuempfle et al. 2013) but some of the most common are gastrointestinal issues and the inability to consume enough calories to offset energy. In the case of self-sufficient events, these factors are compounded by a deliberate decision by athletes to compromise energy intake for reduced load to carry (Alcock et al. 2018; Lucas et al. 2016; McCubbin et al. 2016).

65

During periods of acute carbohydrate $(\mathrm{CHO})$ insufficiency ketone bodies (acetoacetate (AcAc) and beta-hydroxybutyrate $(\beta-\mathrm{HB}))$ are produced as an integral component of homeostasis (Cox and Clarke 2014). As blood glucose and insulin levels drop, free fatty acids are liberated from adipose tissue and partially oxidised in the liver producing ketones (Cahill 1981). The brain can then utilise these circulating ketone bodies for up to $60 \%$ of its energy requirements, the remainder coming from gluconeogenesis (Cox and Clarke 2014; Egan and D'Agostino 2016). Ketones also become an alternate energy source for the heart and skeletal muscle (Cox and Clarke 2014; Egan and D’Agostino 2016) reducing nitrogen depletion and allowing for the retention of lean muscle mass (Cahill 2006). This suggests that during a self-sufficient, multistage ultramarathon when limited by restricted exogenous energy and $\mathrm{CHO}$ sources, being in a state of ketosis may be beneficial to athletes. 
78 In practice however, being in a state of ketosis during athletic endeavours is generally regarded as undesirable due to the initial 'adaptation period' characterised by lethargy and fatigue, as well as the potential for impaired performance due to glycogen depletion, inefficient utilization of muscle substrates, and reduced exercise economy (Burke et al. 2017; Phinney et al. 1983; Yeo et al. 2011). Although metabolic adaptations to low carbohydrate or calorie restricted diets demonstrably occur within five days (Goedecke et al. 1999) it has been suggested that athletes may require several weeks, if not months, to adapt fully (Volek et al. 2016). This may have negative implications for athletes who experience this transition period during multi-stage ultraendurance events.

Early studies on starvation (Azar and Bloom 1963; Bloom and Azar 1963; Cahill 1981;

Consolazio et al. 1968) demonstrated the link between $\mathrm{CHO}$ insufficiency and ketosis.

Consolazio et al. (1968) similarly noted that when in a daily energy deficit of 11.7 MJ (2 800

kcal) induced through fasting and exercise, ketosis could be avoided by ingesting 1.8 MJ (420 $\mathrm{kcal}, \sim 100 \mathrm{~g}$ ) of $\mathrm{CHO}$ per day, an amount equal to the carbohydrate requirements of the brain (Cahill 1981). Subsequent guidelines have thus recommended a daily $\mathrm{CHO}$ intake of $>100 \mathrm{~g}$ combined with a fat intake of less than $160 \mathrm{~g}$ to prevent ketosis during periods of caloric restriction (Marriott 1995; Montain and Young 2003). There is scarce data on ketosis and CHO intake during ultra-endurance exercise. Although the presence of urinary ketones has been reported in athletes during ultra-endurance events and attributed to insufficient $\mathrm{CHO}$ (Costa et al. 2014; Costa et al. 2013), not all studies have reported concomitant CHO intake (Jablan et al. 2017; Weibel and Glonek 2007).

100 
103 There is a growing body of nutrition research in the field of ultra-endurance sports, but the focus

104 is often on races where participants have access to exogenous food supplies through aid stations

105 and/or crew assistance. Nutritional intake during a self-sufficient multi-stage race is restricted to

106 what the participant is prepared to carry from the first day. This is, to our knowledge, the first

107 study to quantify energy, $\mathrm{CHO}$ intake and $\beta$-HB during a fully self-sufficient multi-stage

108 ultramarathon. The aim of this study was to determine changes in blood $\beta$-HB concentration

109 during five days of a self-supported multi-day ultramarathon in combination with quantification

110 of energy and macronutrient intakes.

112 Methods

\section{Ethics statement}

115 Ethical approval was granted by the University of Westminster FST Research Ethics Committee

116 (Application VRE1516-0780). All work was performed in accordance with the principles of the

117 Declaration of Helsinki and participants gave written, informed consent.

\section{Participants}

120 Participants were recruited from the pool of registered competitors via an email sent out by the

121 race organisers. Details of the study were also posted on a social media platform with a request 122 for volunteers.

124 Race conditions

125 The study was conducted during a 7-day self-sufficient, multi-stage ultramarathon in the

126 Namibian Desert in May 2016. Race organisers provided shelter for sleeping (10 person canvas 
tents) and plain water at overnight campsites and plain water only at aid stations positioned approximately $10 \mathrm{~km}$ apart on the course. Competitors were required to carry all other personal and mandatory equipment, including food, in a backpack for the duration of the race. Race regulations stipulated a minimum food requirement of $14000 \mathrm{kcal}$ for the entire race.

132 Course terrain was predominantly sandy (beach, dunes) with some vehicular dirt track, rocky sections and salt pans (hard packed mud and coral-like terrain). Recorded temperatures ranged between $16^{\circ} \mathrm{C}$ at night and $35^{\circ} \mathrm{C}$ during the day (mean daytime temperature $27^{\circ} \mathrm{C} \pm 4^{\circ} \mathrm{C}$ ). Humidity ranged from $25 \%$ to $51 \%$.

The competitors took seven days to complete the race, which totalled $250 \mathrm{~km}$. This investigation took place during the first five days of the race during which the participants completed a total of $240 \mathrm{~km}$. Each day commenced at 08:00 and stage distances for the first four days were: 38

$140 \mathrm{~km}, 42 \mathrm{~km}, 42 \mathrm{~km}$ and $41 \mathrm{~km}$. The fifth day, known as 'the long stage', was $77 \mathrm{~km}$ and 141 competitors were allowed 27 hours to complete the distance. This format is characteristic of this 142 series of races, and in practice results in most competitors having a full 'rest' day on day six which is when the final measures were taken. Upon completion of the $10 \mathrm{~km}$ stage on day 7

144 (which was not included in the study) food and drink were provided by race organisers and then participants had a two hour bus ride back to the host town

\section{Study design}

148 Baseline measures were taken one day prior to the race (pre-race) and on the 'rest day' (day six),

149 a minimum of 12 hours following the finish of the long stage. Blood and food diary data was 150 collected on days one to five. A schematic of the study protocol is provided in Figure 1. 
*** Figure 1 about here $* * * *$

\section{Performance}

155 Although this study was not interventional, data collection took place during a competitive race

156 event. Therefore, finishing times were converted into average velocity $\left(\mathrm{km} \cdot \mathrm{hr}^{-1}\right)$ and used as a

157 measure of performance. Race timings were recorded via timing chips carried by competitors and official results were provided by the race organisers.

\section{Anthropometry}

161 Anthropometric measures were taken with participants in their racing clothes comprised of shorts

162 (males) and shorts and bra tops (females) for both pre- and rest day measures. All participants were sockless and shoeless during the measures. Height was measured pre-race to the nearest 0.1 cm (Seca 213 stadiometer, Seca, Birmingham, UK). Body mass was measured pre-race and on the rest day to the nearest $100 \mathrm{~g}$ (Seca 877 flat scales, Seca, Birmingham, UK). Scales were

166 placed on a wooden board to provide a stable surface in the field.

The sum of skinfolds was determined pre-race and on the rest day using the four-site

169 Durnin/Womersley skinfold method (Durnin and Womersley 1974). Skinfold thicknesses were measured on the right side of the body to the nearest $0.2 \mathrm{~mm}$ using Harpenden skinfold callipers

171 (Baty International, West Sussex, UK). All anthropometric measures were conducted by the same investigator (technical error of measurement (TEM) of 3.5\%)

\section{Glucose and $\beta$-hydroxybutyrate}

175 Every day, immediately post-stage, blood glucose (GLUC) and $\beta$-hydroxybutyrate (KET) were

176 measured via capillary sampling from the fingertip using two CardioChek analysers (Polymer 
177 Technology Systems, Indianapolis, USA) and PTS Panels single-analyte test strip. Each analyser

178 was specific either to GLUC or KET throughout the study. Limits of detection for GLUC and

179 KET were $1.11-33.3 \mathrm{mmol} \cdot \mathrm{L}^{-1}$ and $0.19-6.72 \mathrm{mmol} \cdot \mathrm{L}^{-1}$ respectively. Analyser testing using

180 check strips was performed daily on both analysers.

181

182 Blood samples were collected with participants in a standardised seated posture, immediately on crossing the finish line of the stage. Ketosis was defined as a blood $\beta$-hydroxybutyrate concentration of $\geq 0.5 \mathrm{mmol} \cdot \mathrm{L}^{-1}$ (Volek et al. 2015).

Whilst the assessment of urinary ketones is a convenient and cost effective method in the field, hyper- and hypohydration, both common issues in ultra-endurance events (Hoffman and Stuempfle 2014; Hoffman et al. 2012), can result in false negatives and false positives respectively (Brewster et al. 2017). Urine strip testing is subjective, semi-quantitative and cannot control for how long urine has been sitting in the bladder. Blood analysis of ketones however provides a quantifiable indication of current metabolic state through circulating $\beta$-HB.

\section{Pack weights}

194 All competitors in the race had their packs weighed during check-in and results were provided to the investigators by the race organisers.

197 Food diary and energy intake

198 Participant food intake was restricted to what they chose to carry on day one, therefore similar 199 to the method employed in Stuempfle et al. (2013), individualised food diaries itemising every 200 food product carried on day one were prepared for each participant. The diary was provided to 201 participants at the end of each day for them to identify what and how much they had eaten, as 
well as noting if food had been lost, thrown away or exchanged with/obtained from, another competitor. Food diaries were then collected by the researcher following the last meal of the day prior to the participant retiring for the evening. Analysis of the energy content and macronutrient profile of foods was performed using Nutritics ${ }^{\circledR}$ dietary analysis software (v1.8, Nutritics Ltd,

Dublin, Ireland). All packaged foods were analysed according to manufacturer provided data.

207 Non-packaged foods were entered using equivalent foods existing in the database. Approximately 1 week postrace, participants were sent an email with their nutrition data and asked for clarifications and corrections.

\section{Estimated energy expenditure}

212 To provide a conservative estimate of total daily energy expenditure so as not to overestimate differences in energy balance, three components were calculated for each participant for each

214 day of the study.

1. Sleeping: Predictive equations were used to estimate basal metabolic rate (BMR). The Cunningham (Cunningham 1980) and Harris Benedict (Harris and Benedict 1918) equations are recognised as being appropriate for athletic populations (Thomas et al. 2016), with the former more suitable for females and the latter for males (Jagim et al., 2017). It was assumed that participants slept for 8 hours per 24-hour period.

2. Racing: Metabolic Equivalent of Task (METs) (Ainsworth et al. 2011) were used to calculate the energy expenditure during racing each day based on average moving speed. Participant weight for day one was defined as pre-race weight plus starting backpack. Weight for subsequent days was calculated as pre-race weight plus starting pack weight minus average daily food weight (food eaten the previous day). 
3. Rest: The remaining time (24 hours minus sleep and racing time) was defined as 'rest' and calculated at 1.3 METs (reclining, talking) (Ainsworth et al. 2011).

228

229 Two competitors took $\sim 20$ hours to complete the 'long stage' (day 5). In this instance, the 230 assumptions were 20 hours racing, 1 hour 'rest' post-racing and 3 hours sleep for the 24 hour 231 period. All other participants took less than 15 hours and were therefore estimated to have 8 hours of sleep and at least one hour of rest on this day.

234 Although the thermal effect of food accounts for approximately $10 \%$ of total daily energy expenditure, various factors such as body composition, macronutrient profile, meal timing, exercise and stress can all influence the metabolic response to feeding (Secor 2009). Therefore, rather than adding a blanket $10 \%$ to all estimates of energy expenditure this component has been excluded. The authors recognise this may result in underestimated energy expenditure and resultant calculated deficits.

\section{Statistical analysis}

Statistical analysis was completed using GraphPad Prism 7.4 for Windows (GraphPad Software, La Jolla California USA). All data was tested for normality using Shapiro-Wilk normality tests.

244 Energy intake on day 5 did not pass the test for normality. Repeated measures ANOVA with

245 Tukey's post-hoc analysis was used to determine differences in variables between stages (energy 246 intake and blood measures). Pre-post measures were analysed using paired t-tests and Cohen's d was calculated for effect size.

249 Relationships between variables were determined using Pearson's correlation coefficient. In the 250 case of non-parametric data (energy intake on day 5) Spearman's rank coefficient was utilised. 
251 Relationship strength was classified for the absolute r-value using thresholds of $0.1,0.3$ and 0.5

252 for small, moderate and large respectively (Hopkins et al. 2009). Significance was set at $\mathrm{p}<0.05$.

253 Data are presented as mean \pm standard deviation (SD).

Results

256

257 Seventeen participants from a field of 219 entrants volunteered for the study, of which 13 were included in the final analysis (Table 1). Two withdrew from the race for reasons unrelated to the study (injuries sustained while running), one participant elected to withdraw from the study but continued with the race, and the nutritional data collected from one participant was incomplete and as such, their data was excluded from analysis. The 13 remaining participants represented $6.6 \%$ of the finishing field: eight males ( $5 \%$ of male finishers) and five females $(11 \%$ of female finishers), All participants had trained for the event, had previous ultramarathon experience and none reported cardiovascular or metabolic disorders..

*** Table 1 about here $* * *$

Estimated energy expenditure and energy and macronutrient intakes

Average total estimated energy expenditure for five days of racing was $113.6 \pm 23.6 \mathrm{MJ}$ which equates to $22.7 \pm 6.6 \mathrm{MJ} \cdot \mathrm{day}^{-1}$ and $2.3 \pm 0.9 \mathrm{MJ} \cdot$ hour $^{-1}$ during the racing periods of the day.

272 Compared to the race rules that stipulated competitors must start the race carrying food providing a minimum of $14000 \mathrm{kcal}(58.6 \mathrm{MJ})$, participants carried an average of $63.6 \pm 10.5 \mathrm{MJ}$ on day one $\left(10.6 \pm 1.7 \mathrm{MJ} \cdot \mathrm{day}^{-1}\right)$. Data from two participants were considered as outliers $(>2 \mathrm{SD}$ from 
the mean) with one participant carrying $39.8 \mathrm{MJ}$ and one carrying $88.5 \mathrm{MJ}$ ). The mean total

Mean energy intake over five days of racing was $48.0 \pm 10.0 \mathrm{MJ}\left(9.6 \pm 2.6 \mathrm{MJ} \cdot\right.$ day $^{-1}$, range: 4.75

$-11.5 \mathrm{MJ})$. All participants were in negative energy balance of $64.6 \pm 22.2 \mathrm{MJ}(12.9 \pm 6.3$

$\mathrm{MJ} \cdot$ day $^{-1}$ ) after five days (range: -44.6 to $-2.7 \mathrm{MJ}$ Over the course of the race, no participant consumed all the food they carried from the first day.

282

Participants consumed $301 \pm 106 \mathrm{~g} \cdot \mathrm{day}^{-1} \mathrm{CHO}$, contributing to $53 \%$ of total energy intake. Mean fat (FAT) intake was $85 \pm 33 \mathrm{~g} \cdot \mathrm{day}^{-1}$ and protein (PRO) $85 \pm 35 \mathrm{~g} \cdot$ day $^{-1}$ representing $32 \%$ and $15 \%$ of total energy intake respectively. Corrected for body mass, participants consumed $4.3 \pm$ $1.8 \mathrm{~g} \cdot \mathrm{kg}^{-1} \cdot$ day $^{-1} \mathrm{CHO}$ (range 1.6 to $9.1 \mathrm{~g} \cdot \mathrm{kg}^{-1} \cdot \mathrm{day}^{-1}$ ), $1.2 \pm 0.5 \mathrm{~g} \cdot \mathrm{kg}^{-1} \cdot \mathrm{day}^{-1} \mathrm{FAT}$ (range: 0.6 to

$2.0 \mathrm{~g} \cdot \mathrm{kg}^{-1} \cdot \mathrm{day}^{-1}$ ) and $1.2 \pm 0.6 \mathrm{~g} \cdot \mathrm{kg}^{-1} \cdot \mathrm{day}^{-1}$ PRO (range: 0.4 to $2.6 \mathrm{~g} \cdot \mathrm{kg}^{-1} \cdot \mathrm{day}^{-1}$. Neither absolute nor corrected intakes of energy (Figure 2A) nor macronutrients (Figures 2B, 2C and 2D) differed between stages $(p>0.5)$.

$* * *$ Figure 2 about here $* * *$

\section{Blood glucose and $\beta$-hydroxybutyrate}

Mean GLUC measured at the end of each stage of the race was $4.8 \pm 1.0 \mathrm{mmol} \cdot \mathrm{L}^{-1}$. Mean daily concentrations are presented in Figure 3. Blood glucose did not differ between baseline $(5.1 \pm$ (Mitrakou et al. 1991)) was reported once, in one participant on day five. 
299 No participant registered blood $\beta-\mathrm{HB}>0.5 \mathrm{mmol} \cdot \mathrm{L}^{-1}$ pre-race. Ketosis was observed in four 300 participants on day one and all participants on days two, three and five. There was a significant 301 decrease in KET concentration on day four compared to days three and five in all participants $302(p<0.001)$. On day four, three participants had KET $<0.5 \mathrm{mmol} \cdot \mathrm{L}^{-1}$. However, mean 303 concentrations remained significantly higher than baseline $(p<0.002)$. Three participants (all 304 different to those three with low KET on day four) did not meet the criteria for ketosis on the rest day at least 12 hours following the finish of the long stage. Mean KET during the race was $1.1 \pm 0.6 \mathrm{mmol} \cdot \mathrm{L}^{-1}$.

Performance

310 Participants took $39.9 \pm 7.1$ hours to complete the $240 \mathrm{~km}$ run during the study period at an 311 average velocity of $6.35 \pm 1.0 \mathrm{~km} \cdot \mathrm{hr}^{-1}$ including all stops at checkpoints along the course.

\section{Pack weights}

314 Mean pack weight for the full field of competitors that finished was $9.6 \pm 1.9 \mathrm{~kg}$ (range $5.6-19$ $\mathrm{kg})$. Pack weight of the top 10 finishers was significantly lighter than those that finished in places $11-196(7.66 \pm 1.2 \mathrm{~kg}$ vs $-9.7 \pm 1.9 \mathrm{~kg}, p=0.006)$.

\section{Correlations}

320 Neither absolute nor relative intakes of CHO or FAT correlated with KET (CHO: absolute $\mathrm{r}=$ 0.03, $p=0.9$, relative $r=-0.004, p=0.99$; FAT: absolute $r=-0.14, p=0.65$, relative $r=-0.20$,

$322 p=0.50$ ). There was a strong, negative relationship between both absolute PRO intake and KET $(r=-0.61, p=0.03)$ and relative PRO intake and KET $(r=-0.54, p=0.056)$. 
325 Whilst there were no significant relationships between either daily energy intake or deficit $326\left(\mathrm{MJ}^{-\mathrm{day}^{-1}}\right.$ ) and GLUC (intake $r=-0.19 p=0.53$, deficit $r=-0.12 p=0.71$ ) or KET (intake $r=$ $3270.28, p=0.35$, deficit $r=-0.27, p=0.36$ ), there was a moderate relationship between the 328 cumulative energy deficit and $\operatorname{KET}(r=-0.44, p=0.0002)$.

Performance was not correlated with mean KET $(r=0.22, p=0.47)$ but had a strong relationship with total CHO intake $(r=0.62, p=0.02)$.

333 As the first significant increase in KET occurred on day two, a Pearson correlation analysis was 334 used to assess the relationship between overall performance and the magnitude of $\beta$-HB concentration increase from baseline to day two. There was a large positive relationship between the magnitude of $\beta$-HB increase and overall performance that approached significance $(r=0.54$, $p=0.06$, figure 4$)$.

$* * *$ Figure 4 about here $* * *$

\section{Discussion}

343 To the best of our knowledge this is the first study to investigate blood glucose and $\beta$ -

344 hydroxybutyrate ( $\beta$-HB) concentrations throughout a fully self-sufficient multi-stage 345 ultramarathon and the influence of nutritional intake on these substrates. The main finding is that 346 all participants in this study entered a state of ketosis within two days of the race commencing, 347 with ketosis not correlated with $\mathrm{CHO}$ intake. 
349 Historically, an energy deficit per se has not been considered enough to induce ketosis

350 (Consolazio et al. 1968): a concomitant reduction in CHO availability to less than $100 \mathrm{~g}$ must

351 occur. Here we show that despite a similar caloric deficit as that induced by Consolazio et al.

352 (1968) ketosis still occurred in all participants despite a mean intake of $301 \pm 106 \mathrm{~g} \cdot \mathrm{day}^{-1}$.

353 Furthermore, ketosis was still evident in participants who consumed up to $600 \mathrm{~g} \cdot \mathrm{day}^{-1}$ of CHO.

354 This lack of relationship between macronutrient intake and ketosis but large relationship between cumulative energy deficit and ketosis suggests that the magnitude of the ongoing energy deficit and the manner in which it is induced (i.e. exercise induced vs energy restriction) may play a greater role than previously appreciated.

359 Prior studies have also noted the presence of urinary ketones in ultra-endurance athletes despite apparently adequate CHO intakes (Costa et al. 2014; Costa et al. 2013; Jablan et al. 2017; Weibel and Glonek 2007). Costa et al. (2013) noted that $46 \%$ of runners in a multi-day ultramarathon (5 days, $225 \mathrm{~km}$ ) presented with urinary ketones indicative of ketosis at least once during the race despite CHO intakes of $520 \mathrm{~g} \cdot \mathrm{day}^{-1}\left(7.5 \mathrm{~g} \cdot \mathrm{kg} \cdot \mathrm{day}^{-1}\right)$. Likewise, in a 24 hour ultramarathon, urinary ketones were present in $90 \%$ of runners whose average $\mathrm{CHO}$ intake was $881 \mathrm{~g}\left(37 \mathrm{~g} \cdot \mathrm{hr}^{-}\right.$ $\left.{ }^{1}\right)$ (Costa et al. 2014). Weibel and Glonek (2007) found that in a six day race, 22 of 31 study participants produced urinary ketones, and although dietary intake was not recorded, they observed that some participants produced urinary ketones despite apparent high $\mathrm{CHO}$ intake. Likewise Jablan et al. (2017) reported a significant increase in urinary ketones in $81 \%$ of participants following a mountain ultra-marathon (mean race time $8.40 \pm 1.28$ hours) although

370 CHO intake was not quantified. All these studies have attributed the presence of urinary ketones to insufficient $\mathrm{CHO}$ intake, but have not further explored the physiological implications of these

372 findings. We suggest that rather than simply being an indication of participants not meeting $\mathrm{CHO}$ 373 recommendations for performance, ketosis may be inevitable during certain ultra-endurance 
events and that athletes will compete in a different physiological state than that which can be assumed for races where external supplies are available. This has practical implications for the self-sufficient, multi-stage athlete who must then manage the negative impacts of such an extreme dietary and metabolic shift whilst competing in an already physiologically stressful situation.

Although fat-oxidation rates have been shown to double following a ketogenic diet, this has not translated into performance improvements for elite endurance athletes (Burke et al. 2017; McSwiney et al. 2018). However, a benefit may exist for ultra-endurance athletes who are working at lower intensities for much longer periods of time with low $\mathrm{CHO}$ availability (Burke 2015). Recent evidence also suggests that long-term 'keto-adapted' athletes (those regularly in a ketogenic state for at least 6 months) not only have equivalent glycogen stores compared to athletes on high $\mathrm{CHO}$ diets, but are also able to replenish these stores in the absence of dietary CHO (Volek et al. 2016). This may be a crucial benefit for multi-stage athletes trying to recover for subsequent days of racing and suggests that incorporating periods of ketosis into training periods may better prepare athletes for these types of competitions. It is plausible that when confronted with such large energy deficits, athletes with greater metabolic flexibility, and specifically the ability to produce and utilise ketones more quickly would perform better. Our results show a trend in this direction and since to the best of our knowledge there are no studies quantifying the 'efficiency' of ketosis (how quickly people may become ketogenic without side effects), this deserves further exploration in future research. These results also raise the question of whether athletes might benefit from starting their events already in nutritional ketosis (without energy restriction) to avoid the adaptation period while racing. 
398 In the present study we report a strong relationship between CHO intake and performance.

399 Carbohydrate is undoubtedly ergogenic and we would expect to see increased CHO intake

400 improve performance in ultra-endurance events (Mahon et al. 2014; Stellingwerff and Cox 2014).

401 However, nutritional intakes in this study were constrained by food choices made by the

402 participants prior to starting the race. While evening meals were of similar composition across

403 the cohort (typically commercial freeze-dried meals) the faster competitors took a higher

404 proportion of 'sports nutrition' products (gels, bars) for daytime consumption which were higher

405 in CHO than 'real' foods taken by the slower competitors (meat jerky, nuts, seeds, cheese). It

406 therefore cannot be ruled out that $\mathrm{CHO}$ intake may have been coincidental to better performance

407 rather than causal. Since total weight of food is a key consideration, it is unclear as to whether

$408 \mathrm{CHO}$ or total energy should be prioritised when optimising race nutrition for a self-supported event. The magnitude of the energy deficit induced by physical exercise in these events suggests that increasing energy content using energy dense high fat foods may improve performance, but

411 the performance benefits of $\mathrm{CHO}$ are undeniable, as long as they are available.

412

413 There is little data on the relationship between increased pack weight through increased 414 nutritional supplies (and therefore intake) and performance in multi-stage races. A recent case415 study suggests the benefits of increased energy consumption outweigh the detriments associated 416 with an increase in pack weight (Alcock et al. 2018), although carrying enough food to meet 417 energy requirements resulted in a pack weight of $14 \mathrm{~kg}$. This contrasts with the mean $7.6 \mathrm{~kg}$ 418 carried by the top 10 competitors in this race and is more than 2.5 times the weight of the pack 419 of the winning competitor. The current literature provides little incentive to increase weight 420 carried if athletes are already performing well with much lighter packs and concomitant reduced 421 energy consumption. In these circumstances, these findings should direct future research into 
appropriate training and preparation to attenuate potential ketogenic adaptation issues during races and optimise performance.

$\beta$-hydroxybutyrate levels were not different from baseline on day one, however, we observed a significant 5.4 fold increase from baseline on day two $\left(0.25 \pm 0.08 \mathrm{mmol} \cdot \mathrm{L}^{-1}\right.$ to $1.35 \pm 0.60$ $\left.\mathrm{mmol} \cdot \mathrm{L}^{-1}, \mathrm{p}=0.0003\right)$, which rose to a 6.4 fold increase from baseline on day three $(0.25 \pm 0.08$ $\mathrm{mmol} \cdot \mathrm{L}^{-1}$ to $\left.1.6 \pm 0.57 \mathrm{mmol} \cdot \mathrm{L}^{-1}, \mathrm{p}<0.0001\right)$. All participants exhibited reduced $\mathrm{KET}$ on day four, albeit still significantly higher than baseline, and KET increased again on days five and six.

The universal drop in KET on day four was unexpected and does not have a ready explanation given that it was unrelated to macronutrient intakes or changes in physical activity. Although speculative, the combined GLUC and KET pattern is indicative of the starvation response as identified by Cahill (1976), the initial stages of which have distinct adaptation phases. Previously consumed meals will provide fuel for up to eight hours. During the subsequent 24 - 48 hours, liver glycogen is used to maintain glucose homeostasis and ketone production increases. Thereafter, as liver glycogen is depleted, gluconeogenesis increases while ketone utilization 437 reduces the demand for glucose from tissues. This results in a temporary increase in blood glucose and concomitant drop in ketone production. After four to five days, major adaptations to energy metabolism occur and ketone utilization increases with a concurrent reduction in gluconeogenesis (Cahill 1976). The starvation response has previously been identified in athletes

441 participating in a $1230 \mathrm{~km}$ ultra-endurance cycling event (Geesmann et al. 2017). During the 54 442 hour event, Geesmann et al. (2017) found that an energy deficit of $23.2 \pm 19.1 \mathrm{MJ}$ resulted in the suppression of testosterone, leptin and IGF-1. In some athletes these remained supressed for up

444 to three days despite ad-libitum intake during recovery. Given the large energy deficits 445 accumulated over five days by participants in this study, further research into the effects of 446 starvation on the metabolic and hormonal health of ultra-endurance athletes is warranted. This is 
447 of particular concern for athletes who train for, and compete in, several self-sufficient multi448 stage ultra-endurance events per year.

450 While a major strength of this study was its applied nature, contributing to understanding 451 metabolic shifts in athletes in a real-world, competitive environment, limitations must be 452 considered. Energy expenditure was not directly quantified but the estimated energy expenditure of $2.3 \mathrm{MJ} \cdot \mathrm{hr}^{-1}$ whilst racing is in line with previous studies on ultra-endurance racing. 454 These include a $24 \mathrm{hr}$ trail race $\left(2.3 \mathrm{MJ} \cdot \mathrm{hr}^{-1}\right)$ (Costa et al. 2014), a $24 \mathrm{hr}$ lab-simulated adventure

race $\left(3.1 \mathrm{MJ} \cdot \mathrm{hr}^{-1}\right)$, and a 6 day adventure race $\left(2.1 \mathrm{MJ} \cdot \mathrm{hr}^{-1}\right)$ (Enqvist et al. 2010). The average 456 daily energy expenditure in our study $\left(22.7 \mathrm{MJ} \cdot\right.$ day $\left.^{-1}\right)$ was larger than previously reported for a 457 multi-day ultramarathon of a similar format (5 days, $225 \mathrm{~km}, 16.0$ to $20.0 \mathrm{MJ} \cdot$ day $\left.^{-1}\right)($ Costa et al. 458 2013) although in the study of Costa et al. (2013) overall distance and running time was less than our study. Additionally, participants in the study of Costa et al. (2013) had their food and equipment transported each day meaning that they could take, and thus consume, more food

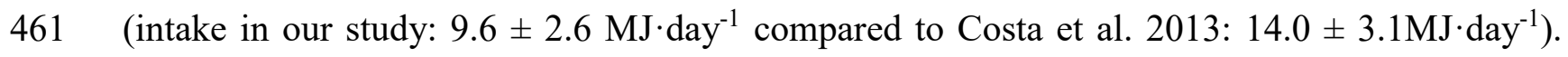

462 Furthermore, this daily transportation of provisions also means load carriage was reduced, potentially resulting in a lower energy expenditure (Lucas et al. 2016), given that the cohort in the present study had a mean starting pack weight of $8.6 \mathrm{~kg}$. Therefore, we believe estimates of energy expenditure and subsequent deficits in the present study are reasonable.

467 Due to logistical constraints in the field, morning pre-stage data collection of blood substrates was not possible but would have added a greater understanding of changes over the course of the race. Furthermore, although capillary testing is a well-recognised method of measuring ketones

470 (Brewster et al. 2017), venous blood samples could take into account changes in blood plasma 471 volume as well as identifying other biomarkers. It has been shown that blood plasma volume 
increases over the course of a multi-stage ultramarathon (Alcock et al. 2018; Costa et al. 2014) suggesting that the participants' ketone levels may have been even higher than recorded. However, given the remote nature of this race the logistics of storing, transporting and analysing whole blood was beyond the scope of the study.

\section{Conclusion}

478 Health and performance related issues in ultra-endurance athletes have been well established and the focus is currently on solving these issues (e.g. gut-training for optimal CHO intake). Unlike races where optimal nutritional strategies may be applied through external access to food selfsufficient multi-stage ultra-marathons restrict intake to the load the athlete is prepared to carry from day one.. This is the first study to document changes in blood glucose and $\beta-\mathrm{HB}$ concentrations and concomitant nutritional intakes during a self-sufficient multi-stage ultramarathon. We showed that all participants were ketogenic by day two. This suggests that rather than being a nutritional choice, competing in a state of ketosis may be unavoidable in multi-stage events where load carriage considerations encourage energy and $\mathrm{CHO}$ restriction. .Given the potential negative impacts associated with such an extreme metabolic shift in athletes unaccustomed to such restriction (fatigue, increased perceived effort and changes to the hormonal milieu), prior keto-adaptation could be a useful strategy to improve health and performance in these athletes, however further work is required to elucidate the benefits of such an approach.

492

Acknowledgements

494 The authors wish to thank the all the participants whose willingness to participate and generosity 495 of spirit in staying with it all until the end is greatly, and gratefully, appreciated. Thanks also go 
497 willingness in allowing the research to take place.

References

Ainsworth, BE, Haskell, WL, Herrmann, SD, Meckes, N, Bassett Jr, DR, Tudor-Locke, C, Greer, JL, Vezina, J, Whitt-Glover, MC \& Leon, AS, (2011), '2011 compendium of physical activities: A second update of codes and met values', Med. Sci. Sports Exerc., 43 (8): 1575-1581. https://sites.google.com/site/compendiumofphysicalactivities/compendia

Alcock, R, McCubbin, A, Camões-Costa, V \& Costa, RJ, (2018), 'Case study: Providing nutritional support to an ultraendurance runner in preparation for a self-sufficient multistage ultramarathon: Rationed versus full energy provisions', Wilderness Environ. Med., 29 (4): 508-520.

508

Azar, GJ \& Bloom, WL, (1963), 'Similarities of carbohydrate deficiency and fasting: li. Ketones, nonesterified fatty acids, and nitrogen excretion', Arch. Intern. Med., 112 (3): 338-343. doi:10.1001/archinte.1963.03860030092007

Bloom, WL \& Azar, GJ, (1963), 'Similarities of carbohydrate deficiency and fasting: I. Weight loss, electrolyte excretion, and fatigue', Arch. Intern. Med., 112 (3): 333-337. doi:10.1001/archinte.1963.03860030087006

Brewster, S, Curtis, L \& Poole, R, (2017), 'Urine versus blood ketones', Practical Diabetes, 34 (1): 13-15. doi:10.1002/pdi.2070

Burke, LM, (2015), 'Re-examining high-fat diets for sports performance: Did we call the 'nail in the coffin' too soon?', Sports Med., 45 (1): 33-49. doi:10.1007/s4027

Burke, LM, Ross, ML, Garvican-Lewis, LA, Welvaert, M, Heikura, IA, Forbes, SG, Mirtschin, JG, Cato, LE, Strobel, N \& Sharma, AP, (2017), 'Low carbohydrate, high fat diet impairs exercise economy and negates the performance benefit from intensified training in elite race walkers', The Journal of Physiology, 595 (9): 2785-2807. doi:10.1113/JP273230

Cahill, GFJ, (1976), 'Starvation in man', Clin. Endocrinol. Metab., 5 (2): 397-415. doi:10.1016/S0300$595 \times(76) 80028-\mathrm{X}$

Cahill, GFJ, (1981), 'Ketosis', Kidney Int., 20 (416-425. https://www.kidneyinternational.org/article/S0085-2538(15)32572-2/pdf

Cahill, GFJ, (2006), 'Fuel metabolism in starvation', Annu. Rev. Nutr., 26 (1-22. doi:10.1146/annurev.nutr.26.061505.111258

Consolazio, CF, Matoush, LO, Johnson, HL, Krzywicki, HJ, Isaac, GJ \& Witt, NF, (1968), 'Metabolic aspects of calorie restriction: Hypohydration effects on body weight and blood parameters', Am. J. Clin. Nutr., 21 (793-802. doi:10.1093/ajcn/21.8.793 
Costa, RJS, Gill, SK, Hankey, J, Wright, A \& Marczak, S, (2014), 'Perturbed energy balance and hydration status in ultra-endurance runners during a 24 h ultra-marathon', Br. J. Nutr., 112 (3): 428-437. doi:10.1017/S0007114514000907

Costa, RJS, Snipe, RMJ, Camões-Costa, V, Scheer, V \& Murray, A, (2016), 'The impact of gastrointestinal symptoms and dermatological injuries on nutritional intake and hydration status during ultramarathon events', Sports medicine-open, 2 (1): 16. doi:10.1186/s40798-015-0041-9

Costa, RJS, Snipe, RMJ, Kitic, CM \& Gibson, PR, (2017), 'Systematic review: Exercise - induced gastrointestinal syndrome_implications for health and intestinal disease', Aliment. Pharmacol. Ther. doi:10.1111/apt.14157

Costa, RJS, Swancott, AJM, Gill, SK, Hankey, J, Scheer, V, Murray, A \& Thake, CD, (2013), 'Compromised energy and macronutrient intake of ultra-endurance runners during a multi-stage ultra-marathon conducted in a hot ambient environment', International Journal of Sports Science, 3 (1): 51-62. doi:10.5923/j.sports.20130302.03

Cox, PJ \& Clarke, K, (2014), 'Acute nutritional ketosis: Implications for exercise performance and metabolism', Extreme physiology \& medicine, 3 (1): 17. doi:10.1186/2046-7648-3-17

Cunningham, JJ, (1980), 'A reanalysis of the factors influencing basal metabolic rate in normal adults', The American journal of clinical nutrition, 33 (11): 2372-2374. doi:10.1093/ajcn/33.11.2372

Durnin, JV \& Womersley, J, (1974), 'Body fat assessed from total body density and its estimation from skinfold thickness: Measurements on 481 men and women aged from 16 to 72 years', Br. J. Nutr., 32 (1): 77-97. doi:10.1079/BJN19740060

Egan, B \& D'Agostino, DP, (2016), 'Fueling performance: Ketones enter the mix', Cell Metab., 24 (3): 373-375. doi:10.1016/j.cmet.2016.08.021

Geesmann, B, Gibbs, JC, Mester, J \& Koehler, K, (2017), 'Association between energy balance and metabolic hormone suppression during ultraendurance exercise', Int. J. Sports Physiol. Perform., 12 (7): 984-989. doi:10.1123/ijspp.2016-0061

Goedecke, JH, Christie, C, Wilson, G, Dennis, SC, Noakes, TD, Hopkins, WG \& Lambert, EV, (1999), 'Metabolic adaptations to a high-fat diet in endurance cyclists', Metabolism-Clinical and Experimental, 48 (12): 1509-1517. doi:10.1016/S0026-0495(99)90238-X

Harris, JA \& Benedict, FG, (1918), 'A biometric study of human basal metabolism', Proceedings of the $\begin{array}{llllll}\text { National Academy of } & \text { 3ciences, } & \text { 370-373. }\end{array}$ https://www.ncbi.nlm.nih.gov/pmc/articles/PMC1091498/pdf/pnas01945-0018.pdf

Hoffman, MD \& Stuempfle, KJ, (2014), 'Hydration strategies, weight change and performance in a 161 km ultramarathon', Res. Sports Med., 22 (3): 213-225. doi:10.1080/15438627.2014.915838

Hoffman, MD, Stuempfle, KJ, Rogers, IR, Weschler, LB \& Hew-Butler, T, (2012), 'Hyponatremia in the 2009 161-km western states endurance run', Int. J. Sports Physiol. Perform., 7 (1): 6-10. doi:10.1123/ijspp.7.1.6 
Hopkins, WG, Marshall, SW, Batterham, AM \& Hanin, J, (2009), 'Progressive statistics for studies in sports medicine and exercise science', Med. Sci. Sports Exerc., 41 (1): 3-12. doi:10.1249/MSS.0b013e31818cb278

Jablan, J, Inić, S, Stosnach, H, Hadžiabdić, MO, Vujić, L \& Domijan, A-M, (2017), 'Level of minerals and trace elements in the urine of the participants of mountain ultra-marathon race', J. Trace Elem. Med. Biol., 41 (54-59. doi:10.1016/j.jtemb.2017.02.004

Lucas, SJ, Helge, JW, Schütz, UH, Goldman, RF \& Cotter, JD, (2016), 'Moving in extreme environments: Extreme loading; carriage versus distance', Extreme physiology \& medicine, 5 (1): 6. doi:10.1186/s13728-016-0047-z

Mahon, E, Hackett, A, Stott, T, George, K \& Davies, I, (2014), 'Macronutrient consumption prior to, and during, a mountain marathon', Am J Sports Sci, 2 (1): 5-12. doi:10.11648/j.ajss.20140201.12

Marriott, BM (ed.) 1995, Not eating enough: Overcoming underconsumption of military operational rations, National Academies Press, Washington, D.C., DOI 10.17226/5002.

McCubbin, AJ, Cox, GR \& Broad, EM, (2016), 'Case study: Nutrition planning and intake for marathon des sables-a series of five runners', Int. J. Sport Nutr. Exerc. Metab., 26 (6): 581-587. doi:10.1123/ijsnem.2016-0016

McSwiney, FT, Wardrop, B, Hyde, PN, Lafountain, RA, Volek, JS \& Doyle, L, (2018), 'Keto-adaptation enhances exercise performance and body composition responses to training in endurance athletes', Metabolism, 81 (25-34. doi:10.1016/j.metabol.2017.10.010

Mitrakou, A, Ryan, C, Veneman, T, Mokan, M, Jenssen, T, Kiss, I, Durrant, J, Cryer, P \& Gerich, J, (1991), 'Hierarchy of glycemic thresholds for counterregulatory hormone secretion, symptoms, and cerebral dysfunction', American Journal of Physiology-Endocrinology And Metabolism, 260 (1): E67-E74. doi:10.1152/ajpendo.1991.260.1.E67

Montain, SJ \& Young, AJ, (2003), 'Diet and physical performance', Appetite, 40 (3): 255-267. doi:10.1016/S0195-6663(03)00011-4

Phinney, SD, Bistrian, BR, Wolfe, R \& Blackburn, G, (1983), 'The human metabolic response to chronic ketosis without caloric restriction: Physical and biochemical adaptation', Metabolism, 32 (8): 757-768. doi:10.1016/0026-0495(83)90106-3

Secor, SM, (2009), 'Specific dynamic action: A review of the postprandial metabolic response', Journal of Comparative Physiology B, 179 (1): 1-56.

Stellingwerff, T \& Cox, GR, (2014), 'Systematic review: Carbohydrate supplementation on exercise performance or capacity of varying durations', Appl. Physiol. Nutr. Metab., 39 (9): 998-1011.

Stuempfle, KJ \& Hoffman, MD, (2015), 'Gastrointestinal distress is common during a 161-km ultramarathon', J. Sports Sci., 33 (17): 1814-1821. doi:10.1080/02640414.2015.1012104

Stuempfle, KJ, Hoffman, MD \& Hew-Butler, T, (2013), 'Association of gastrointestinal distress in ultramarathoners with race diet', Int. J. Sport Nutr. Exerc. Metab., 23 (2): 103-109. 
640 Thomas, DT, Erdman, KA \& Burke, LM, (2016), 'American college of sports medicine joint position 641 statement. Nutrition and athletic performance', Med. Sci. Sports Exerc., 48 (3): 543-568. 642 doi:10.1249/MSS.0000000000000852

643

644 Volek, JS, Freidenreich, DJ, Saenz, C, Kunces, L, Creighton, BC, Bartley, JM, Davitt, PM, Munoz, CX, 645 Anderson, JM, Maresh, CM, Lee, EC, Schuenke, MD, Aerni, G, Kraemer, WJ \& Phinney, SD, (2016), 646 'Metabolic characteristics of keto-adapted ultra-endurance runners', Metabolism-Clinical and 647 Experimental, 65 (3): 100-110. doi:10.1016/j.metabol.2015.10.028

648

649

Volek, JS, Noakes, T \& Phinney, SD, (2015), 'Rethinking fat as a fuel for endurance exercise', European

650

651

652

653

654

655

656

657

658

659

660

661 Journal of Sport Science, 15 (1): 13-20. doi:10.1080/17461391.2014.959564

Wardenaar, FC, Dijkhuizen, R, Ceelen, IJ, Jonk, E, De Vries, JH, Witkamp, RF \& Mensink, M, (2015), 'Nutrient intake by ultramarathon runners: Can they meet recommendations?', Int. J. Sport Nutr. Exerc. Metab., 25 (4): 375-386. doi:10.1123/ijsnem.2014-0199

Weibel, J \& Glonek, T, (2007), 'Ketone production in ultra marathon runners', Journal of Sports Medicine and Physical Fitness, 47

(4): 491.

https://search.proquest.com/openview/70e306383a23b34d2b2a2d005d0d6fff/1?pq$\underline{\text { origsite }=\text { gscholar } \& \mathrm{cbl}=4718}$

662

Yeo, WK, Carey, AL, Burke, L, Spriet, LL \& Hawley, JA, (2011), 'Fat adaptation in well-trained athletes: 663 Effects on cell metabolism', Appl. Physiol. Nutr. Metab., 36 (1): 12-22. doi:10.1139/H10-089

664 
Table 1: Participant characteristics

\begin{tabular}{|c|c|c|c|}
\hline & \multicolumn{3}{|c|}{$\begin{array}{l}\text { Participant Characteristics } \\
(n=13,8 \text { males, } 5 \text { females })\end{array}$} \\
\hline & Pre-race & Day 6 & Cohen's $d$ \\
\hline Age (years) & $40 \pm 8$ & - & \\
\hline Height (cm) & $175.1 \pm 8.1$ & - & \\
\hline Body mass (kg) & $73.1 \pm 11.8$ & $70.6 \pm 11.6 *$ & 0.1 \\
\hline Sum of 4 skinfolds (mm) & $38.1 \pm 12.2$ & $32.0 \pm 10.8 *$ & 0.3 \\
\hline Starting pack weight (kg) & $8.6 \pm 1.3$ & - & \\
\hline
\end{tabular}

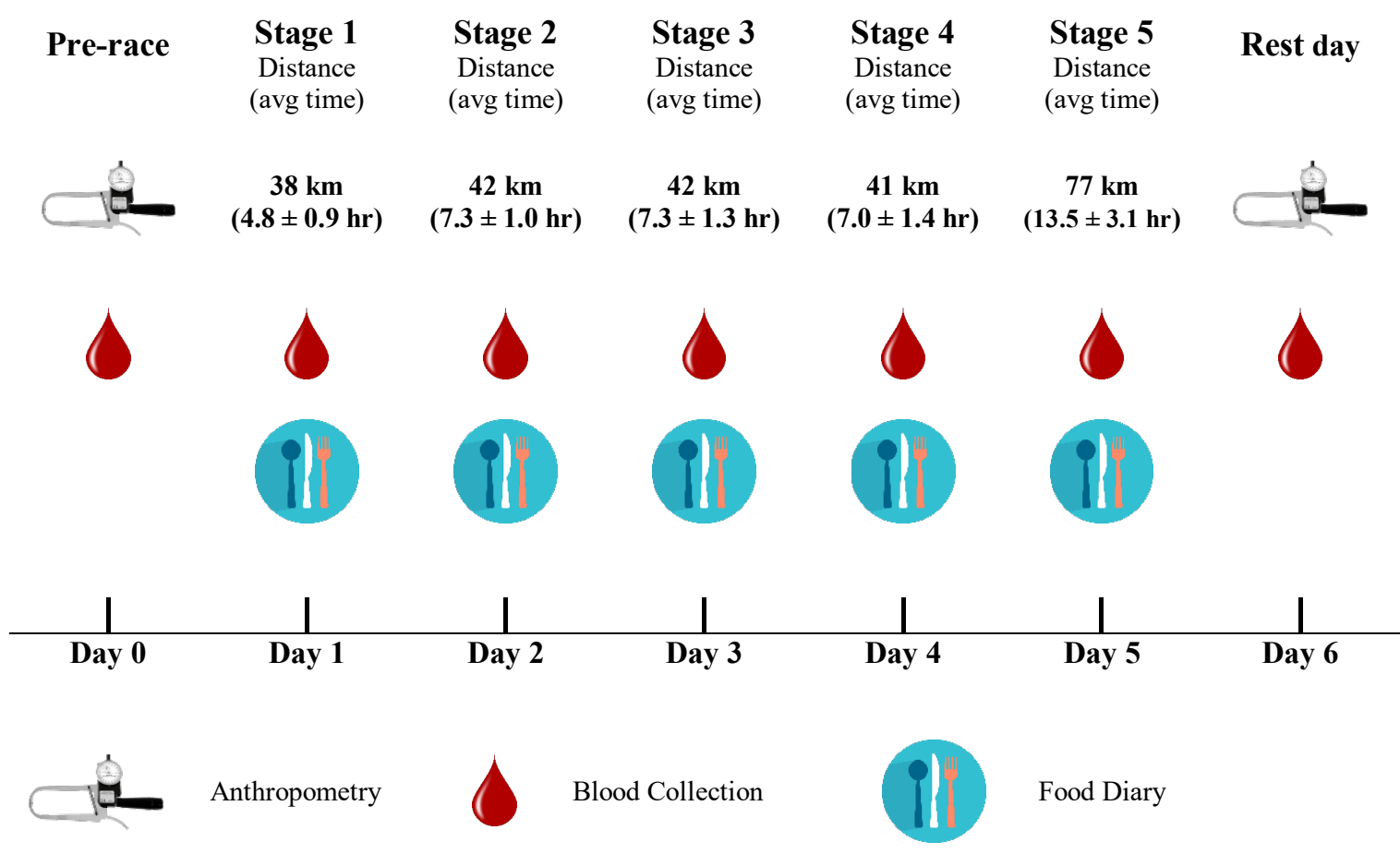

Figure 1. Schematic of study protocol. Blood samples were taken immediately post-stage every day at the finish line 
A)

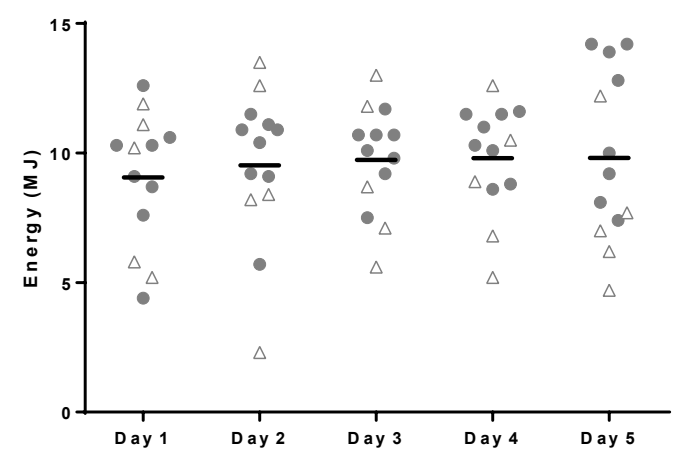

C)

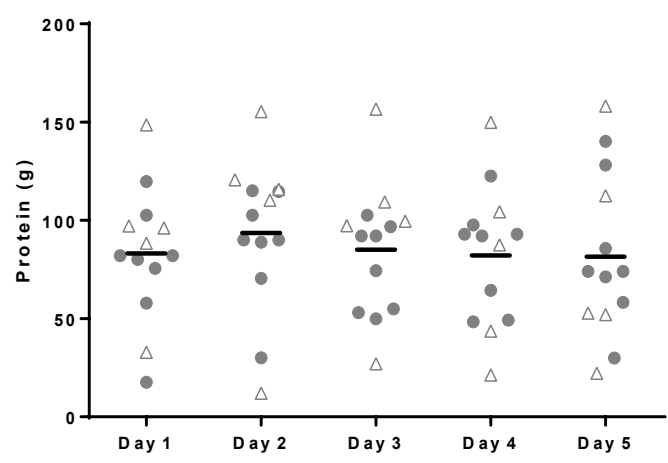

B)

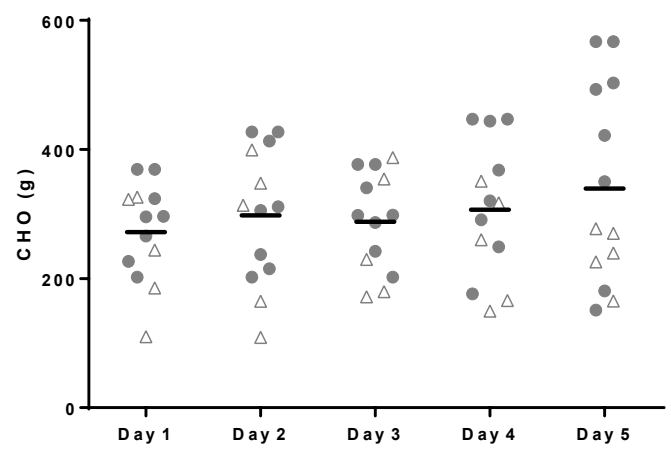

D)

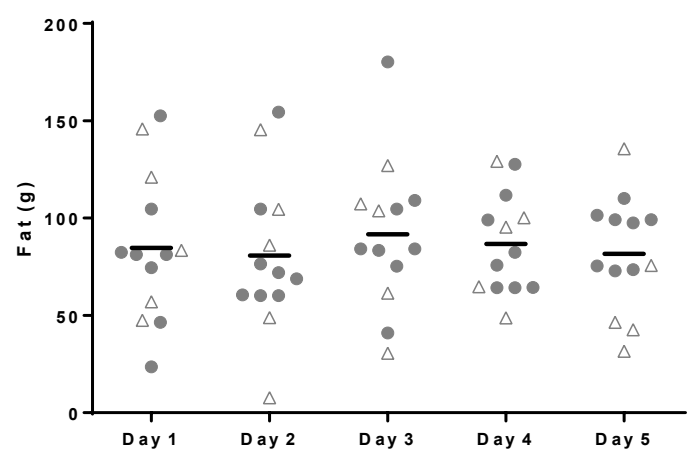

Figure 2: Mean daily intakes of (A) energy, (B) CHO, (C) PRO and (D) FAT. $\Delta$ Female; $\bullet$ Male. Bars indicate mean intake 


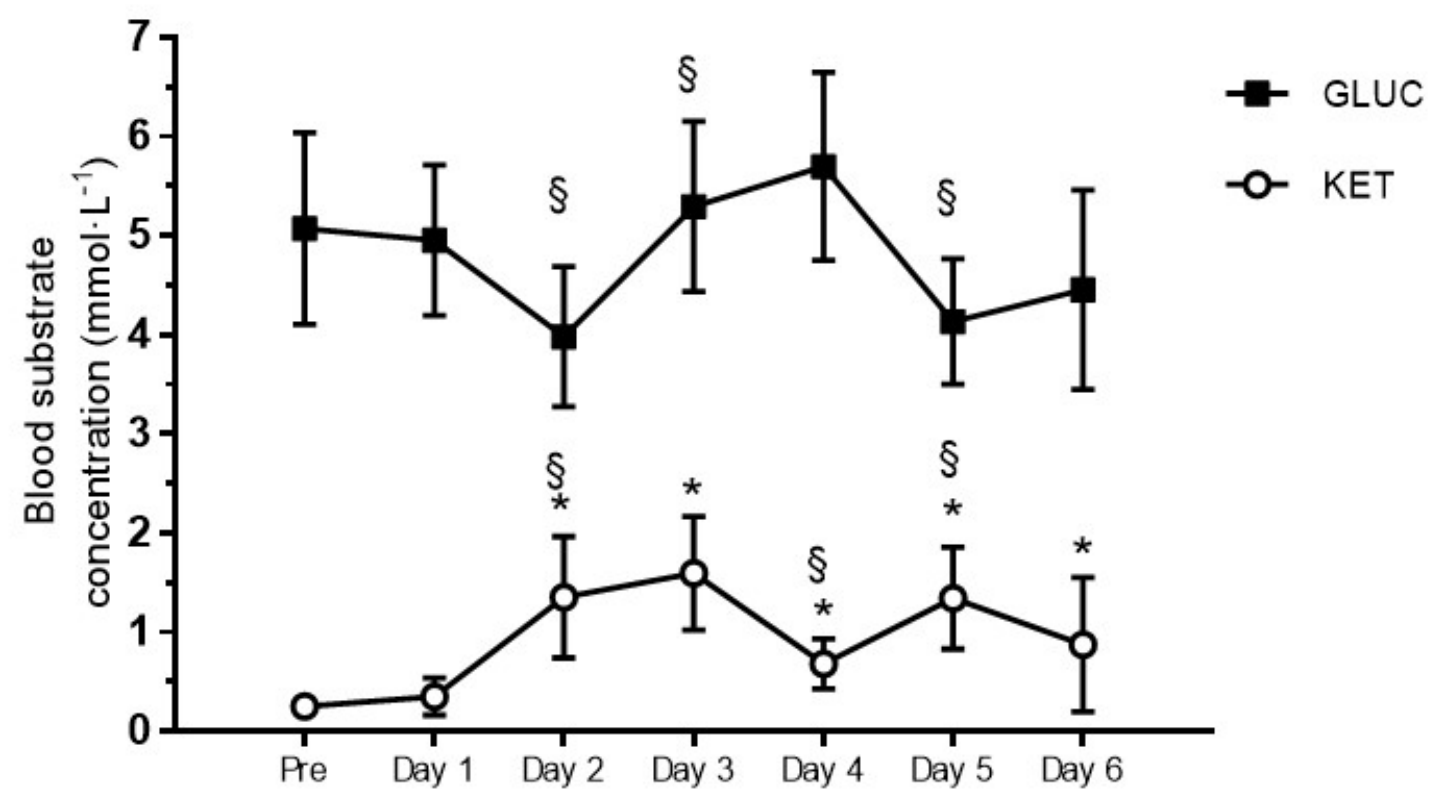

Figure 3. Blood GLUC and KET concentrations. * denotes a significant change from baseline. $\S$ denotes a significant change from the day before. Data are presented as mean $\pm \mathrm{SD}$.

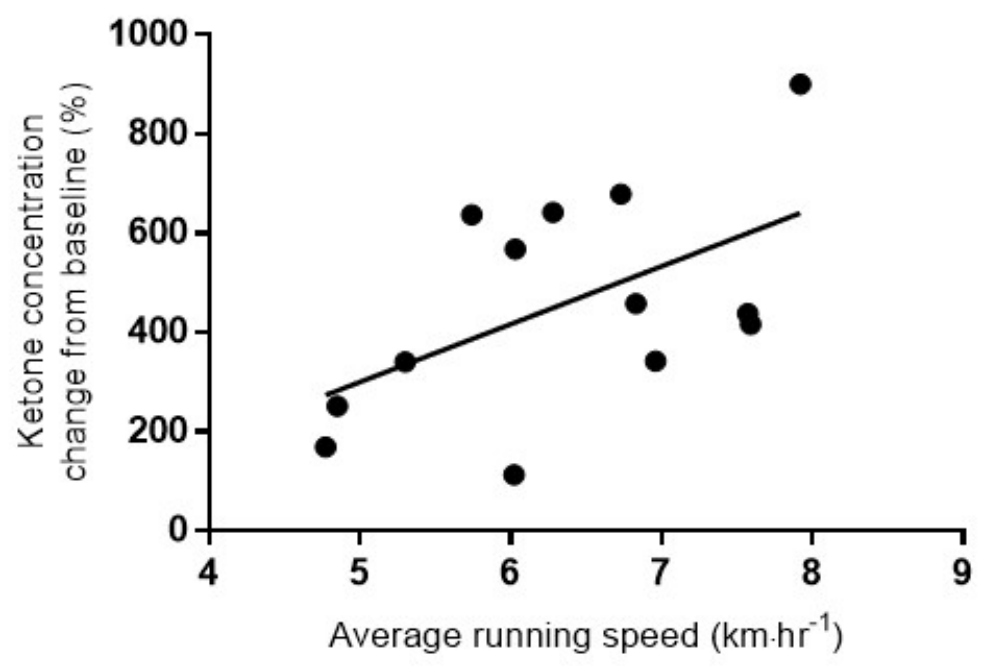

Figure 4. The relationship between the change in ketone concentration from baseline on day two and overall performance as defined by average speed throughout the race $(r=0.54, p=0.06)$ 